\title{
ANTROPOLOGÍA CRISTIANA, DESARROLLO HUMANO Y ESCUELA AUSTRIACA: UN DIÁLOGO INTERDISCIPLINAR
}

\author{
JOSÉ MARÍA LARRÚ1
}

Fecha de recepción: 4 de noviembre de 2014

Fecha de aceptación: 10 de marzo de 2016

Resumen: El artículo pone en diálogo interdisciplinar la antropología cristiana, la doctrina social de la lglesia, el paradigma del desarrollo humano de Naciones Unidas y la economía de la escuela austriaca. Enfatiza que la principal diferencia entre ellas es la antropología cristiana fundamentada en el personalismo trascendental, pero que existen puntos metodológicos en común. En el pensamiento cristiano y el liberalismo austriaco, el desarrollo humano es dinámico, integral (de todo el hombre y para todos los hombres), solidario (bajo la subsidiariedad). Pero en la visión cristiana, el destino universal de los bienes limita la propiedad privada, la libertad no es un absoluto y la persona es un ser social, no sólo individuo. Además, el desarrollo cristiano se centra y culmina en el amor de caridad que supera el altruismo y la búsqueda del bien común se hace en comunidad de discernimiento, donde la opción por el pobre se hace prioritaria, la opción por la justicia es ineludible si la fe profesada es verdadera. El orden espontáneo y el conocimiento disperso, la posibilidad de ganancia empresarial como motor de la creación de riqueza son principios compartidos por la doctrina católica, aunque con evidentes matices. El artículo muestra que es posible el enriquecimiento mutuo entre disciplinas tan diversas, pero que al tener un fundamento en la ética y en la antropología, que nunca deben estar ausentes de la economía, el rechazo frontal entre liberalismo y doctrina católica es un anacronismo que debe ser superado.

Palabras clave: amor, desarrollo, pobreza, riqueza, orden espontáneo, Escuela austriaca

\footnotetext{
${ }^{1}$ Universidad CEU San Pablo. larram@ceu.es
} 
Title: Christian anthropology, human development and Austrian economics: a interdisciplinary dialogue.

Abstract: The article suggests an interdisciplinary dialogue among Christian anthropology, the social doctrine of the Church, the human development paradigm of the UN and the economics of the Austrian school. It emphasizes that the main difference between them is that Christian anthropology is based on transcendental personalism, but there are methodological points in common. In Christian thought and Austrian liberalism, human development is dynamic, integral (of the whole man and for all men), solidary (under the subsidiarity principle). But under the Christian view, the universal destination of goods limits private property, freedom is not absolute and the person is a social being, not just an individual. In addition, the Christian idea of development centers and culminates in charity that goes beyond altruism and common good is done in community discernment where the option for the poor is a priority, the option for justice is inescapable if the professed faith is true. Spontaneous order and dispersed knowledge, the possibility of entrepreneurial profit as an engine of wealth creation are shared by Catholic doctrine, though with obvious nuances principles. The article shows that it is possible to cross-fertilization between disciplines as diverse, but to have a foundation in ethics and anthropology, which should never be absent from the economy. The outright rejection of liberalism and Catholic doctrine is an anachronism that should be overcome.

Key words: love, development, poverty, wealth, spontaneous order, Austrian school

JEL Classification: A13, B53, Z12, O1.

INTRODUCCIÓN

La religión no ha sido considerada tradicionalmente una de las dimensiones del desarrollo humano, lo cual no deja de ser irónico dado que la cooperación internacional al desarrollo puede tener un antecedente en las misiones religiosas de la era colonial y por la significatividad de la religión en los proyectos de vida cotidiana de mucha de la población pobre. Quizá, como señala Carbonnier (2013) la influencia del positivismo comtiano en la Ilustración y su 
empeño en desligar sin posibilidad de diálogo la ciencia de la religión, así la modernidad y la secularización durante el siglo XX en los países desarrollados, empeñándose en una separación radical entre iglesias y estado, intentando recluir a la religión en la esfera estrictamente privada, tiene sin duda cierta carga explicativa en lo anterior. Sin embargo, hay un revival de lo religioso y el desarrollo. Por ejemplo Carbonnier cita tres iniciativas de agencias internacionales de desarrollo relacionadas con el hecho religioso: el UK Religious and Research Programme Consortium; el Dutch Religion and Development Knowledge Centre y el Swiss reflection on the Role and Significance of Religion and Spirituality. El Banco Mundial mantiene una línea de trabajo (Development Dialogue on Values and Ethics) en coordinación con la iniciativa World Faiths Development Dialogue lanzada en 2000 por el entonces director del Banco J. Wolfensohn y el arzobispo de Canterbury G. Carey. Pensemos además que, según el World Christian Database y el Pew Forum on Religion and Public Life más de 5.000 millones de los 7.500 millones de habitantes del planeta confiesan alguna religión ${ }^{2}$.

El objetivo de este trabajo es hacer un análisis exploratorio sobre la potencial contribución de la antropología cristiano-católica al concepto de desarrollo humano. Se trata de poner a dialogar la reflexión cristiana sobre el hombre con la idea de desarrollo que elabora el PNUD bebiendo del pensamiento de Cornia et al. (1987), ul Haq y de A.K. Sen (2000) y —más originalmente-con el pensamiento antropológico y metodológico de la Escuela Austriaca de economía.

La principal originalidad del estudio es plantear el valor de amor de caridad como el sustento de las relaciones entre los hombres que son individuos y personas, y en cuanto tales, seres sociales, seres en relación. La imagen propia del Dios cristiano es que es precisamente amor puro («Dios es amor» 1Jn 4,8), y que el hombre ha sido creado a imagen y semejanza de ese Amor, destinado a recibir, recoger y reflejar dicho Amor. Frente a la crítica común de considerar la «caridad» como la antítesis de la justicia, bien

${ }^{2}$ La región con más creyentes es Asia-Pacífico con más de 4.000 millones y entre las religiones destacan los 1.396 millones de sunníes seguidos por los 1.094 millones de católicos y 949 millones de hindúes (Carbonnier 2013:4). 
entendida y profundizada la caridad es la única fuente de verdadera justicia, porque es Dios quien revela al hombre su propia esencia, lo que es verdaderamente humano (GS 22), el único que puede realmente "dar a cada uno lo suyo». Por tanto un desarrollo que no considera el don de sí y al Amor como la dimensión substantiva del hombre no puede ser un desarrollo verdaderamente humano (Bertina 2013), según la creencia cristiana que lejos de imponerse, tampoco debe mostrarse avergonzada en proponerse académicamente.

El método utilizado en el trabajo exige detectar y caer en la cuenta que se entremezclan dos fuentes de conocimiento (razón y fe), hasta tres lenguajes (filosófico, económico y teológico) y un método hipotético-deductivo donde la hermenéutica juega un papel clave. Lo expuesto a continuación consiste en la síntesis siempre dinámica y evolutiva- de lo que interpreto pueden ser nexos comunes entre los discursos de varios agentes de desarrollo (académicos, Naciones Unidas, Iglesia jerarquía) y varios lenguajes. Espero que estas cautelas y la explicitación de que soy creyente hagan que los juicios de valor no opaquen la búsqueda de la verdad y el diálogo interdisciplinar característico de los estudios de desarrollo.

Para realizar la exploración de posibilidades entre Doctrina Social de la Iglesia (DSI), informes de desarrollo humano y método y concepción de orden social de la Escuela Austriaca (EA), he procedido de la siguiente manera. En la sección 2 presento una síntesis de la antropología cristiana para fundamental qué entender por «humano» cuando se piense sobre «desarrollo humano». En la sección 3, expongo algunas ideas fundamentales del tratamiento de la riqueza y pobreza en la Biblia, centrándome sobre todo en la aportación de los sinópticos y la vivencia de Jesús de Nazaret. En la sección 4, presento los mensajes fundamentales de la DSI en materia de «desarrollo humano integral», para - en la sección 5- entrar en el diálogo con las aportaciones del PNUD y de la EA. La sección 6 concluye esta exploración. 

EL HOMBRE IMAGO DEI.

La idea fundamental de este trabajo es hacer ver que la especificidad de la idea cristiana de desarrollo está en su antropología y en el amor como valor supremo que debe orientar las relaciones del hombre consigo mismo, con los demás, con la naturaleza y con la trascendencia (Dios). Aquí voy a resumir de forma breve lo que considero que es lo nuclear de la antropología cristiana y que tiene repercusión en el concepto de desarrollo humano integral, que es usado por la Doctrina Social de la Iglesia (DSI). Una idea subyacente es que el concepto de desarrollo humano de Naciones Unidas, al concebirse de forma laica y no entrar en el ámbito religioso, queda de cierta forma cojo, pues no concreta qué idea de hombre es la que hay que poner en el centro del desarrollo. Pero por otro lado, la DSI no puede hacer propuestas técnicas o de política económica para promocionar de forma concreta dicho proceso de desarrollo, así que ambos discursos podrían entrar en diálogo y enriquecerse mutuamente.

La centralidad de la antropología cristiana es que considera al hombre como imagen de Dios. Esta concepción no es fruto de una deducción racional ni de una inducción a partir de experiencias observadas como haría la antropología filosófica y la antropología cultural. Es fruto del estudio y análisis de la experiencia de fe de un pueblo (Israel) y de la vida de un hombre (Jesucristo) que han marcado buena parte de la historia de Occidente. En efecto, la tradición religiosa judeocristiana no es una espiritualidad, ni una ética, ni una estética, ni una lógica, pero abarca todas ellas. Lo nuclear es que expresa una verdad compartida por muchos y transmitida por generaciones, de una idea de Dios (Yahvé para los judios y Abbá o Dios-Amor para los cristianos) que es el Creador de cuanto existe. En ese acto creador, se incluye al hombre que fue creado a su imagen y semejanza, libre para poder recibir el Amor divino y responder a él libremente. Esa acogida-respuesta (vocación) es la que condiciona todo lo demás: verdad, bondad, belleza, trascendencia, libertad, responsabilidad, trabajo y relaciones sociales (fraternidad). 
Establecido este supuesto central, desarrollaré mi síntesis antropológica en seis puntos que van a definir el par humano tanto en su plano individual como social (el hombre es individuo y sociedad). El esquema básico queda reflejado en la Figura 1.

FIGURA 1

ESQUEMA DE LA ANTROPOLOGÍA CRISTIANA: INDIVIDUO Y SOCIEDAD.

\begin{tabular}{|c|c|c|c|}
\hline $\begin{array}{l}\text { ES único e } \\
\text { irrepetible }\end{array}$ & $\begin{array}{c}\text { ES igual en } \\
\text { dignidad (DD. } \\
\text { HH.) }\end{array}$ & $\begin{array}{c}\text { DEBE ser } \\
\text { (ético y nunca } \\
\text { acabado) }\end{array}$ & $\begin{array}{c}\text { LLEGARÁ a ser } \\
\text { (teleológico, } \\
\text { trascendente) }\end{array}$ \\
\hline \multicolumn{2}{|c|}{ INDIVIDUO } & \multicolumn{2}{|c|}{ SOCIEDAD } \\
\hline \multicolumn{2}{|c|}{$\begin{array}{l}\text { 1. Único e irrepetible: bios, psíque y } \\
\text { espíritu (GS12) }\end{array}$} & \multicolumn{2}{|c|}{ 1. Entra en existencia en sociedad } \\
\hline \multicolumn{2}{|c|}{$\begin{array}{l}\text { 2. Capaz de conocer: realismo } \\
\text { moderado (GS15) }\end{array}$} & \multicolumn{2}{|c|}{$\begin{array}{l}\text { 2. Dependencia esencial de sus } \\
\text { semejantes }\end{array}$} \\
\hline \multicolumn{2}{|c|}{$\begin{array}{l}\text { 3. Capaz de individualizarse: darse } \\
\text { identidad (GS14) }\end{array}$} & \multicolumn{2}{|c|}{ 3. Lenguaje: socialización y subsistencia } \\
\hline \multicolumn{2}{|c|}{$\begin{array}{l}\text { 4. Capaz de autodeterminarse al Bien } \\
\qquad(\mathrm{GS} 13,16,17)\end{array}$} & \multicolumn{2}{|c|}{ 4. El creador de instituciones } \\
\hline \multicolumn{2}{|c|}{$\begin{array}{l}\text { 5. Capaz de trascenderse (deseo } \\
\text { infinito) (GS14) }\end{array}$} & \multicolumn{2}{|c|}{ 5. Aprendiz del bien } \\
\hline \multicolumn{2}{|c|}{$\begin{array}{l}\text { 6. Consciente de su finitud (muerte) } \\
\text { (GS18) }\end{array}$} & \multicolumn{2}{|c|}{ 6. Cultural y violento } \\
\hline
\end{tabular}

Fuente: elaboración propia. GS=números de Gaudium et Spes, Cap. 1 «Dignidad de la persona humana».

\section{El hombre es un ser único e irrepetible y viene al ser en sociedad}

Tanto por biometría, psicología o teología cada individuo es único e irrepetible. Ni siquiera los gemelos univitelinos son idénticos en carácter y sus huellas dactilares pueden llegar a diferenciarse. Cada individuo protagoniza su propia historia y toma sus decisio- 
nes, condicionado por circunstancias, esforzándose, o siendo coaccionado, pero es único. Pero esa individuación es fruto de una sociedad. La concepción exige participación de al menos dos células sexuadas diferentes. El nacimiento de cada ser ocurre en «sociedad» aunque sólo sea por la necesaria presencia de la madre. Normalmente hay mucha «sociedad» rodeando el nacimiento: progenitores, médicos o hermanos que ya estaban ahí cuando devino al nacer.

Además, hombre y mujer son creados iguales en dignidad y esta igualdad primordial es compatible con la unicidad. Así se asemeja a un Creador que es - al tiempo- Uno y Trino (en diversidad de personas, en trinidad-comunidad o sociedad). Así queda reflejado en el uso del plural «hagamos» del relato del Génesis: «hagamos al hombre a nuestra imagen y semejanza» (Gen 1,26) a diferencia del resto de la creación que ha quedado expresada en el singular «y dijo Dios». Y en esta creación se incluyen hombre y mujer, ambos iguales en dignidad, ambos imagen de Dios, sin relación de sometimiento ni precedencia en cuanto a este dato se refiere $\left(\right.$ Gen 1,27) ${ }^{3}$. El relato está lleno de simbolismo al crear Dios al hombre (adam en hebreo) moldeándole con tierra (adamah) e insuflándole su propio espíritu (ruah, que en hebreo es femenino). La mujer será creada en relación de comunión con el varón, a partir de su costilla.

\footnotetext{
${ }^{3}$ Para la defensa de esta común dignidad véase Catecismo de la Iglesia Católica ${ }^{\circ}$ 2334 [ «Creando al hombre "varón y mujer", Dios da la dignidad personal de igual modo al hombre y a la mujer» (FC 22; Cf. GS 49, 2). «El hombre es una persona, y esto se aplica en la misma medida al hombre y a la mujer, porque los dos fueron creados a imagen y semejanza de un Dios personal» (MD 6)] y el no372 («El hombre y la mujer están hechos "el uno para el otro": no que Dios los haya hecho "a medias" e "incompletos"; los ha creado para una comunión de personas, en la que cada uno puede ser "ayuda" para el otro porque son a la vez iguales en cuanto personas ... y complementarios en cuanto masculino y femenino»); Pontificio Consejo Justicia y Paz 2005, $\mathrm{n}^{\circ} 111$ («el hombre y la mujer tienen la misma dignidad y son de igual valor»); o la Carta Apostólica de Juan Pablo II (1988) Mulieris Dignitatem 6 («ambos son seres humanos en el mismo grado, tanto el hombre como la mujer; ambos fueron creados a imagen de Dios»).
} 


\section{El hombre es un ser capaz de conocer y se desarrolla en sociedad}

El hombre posee autoconciencia de sí mismo y es capaz de acceder a la realidad por medio de la interpretación de sus sentidos. Accede de forma realista (moderada) a la realidad mediada por la interpretación en su cerebro. Percibe la realidad al tiempo que la «modifica» en su cerebro. Además crea significados asociando objetos a palabras. Realidad, pensamiento y lenguaje son una tríada inseparable. La inter-subjetividad del lenguaje (que sólo acontece en sociedad) le permite compartir con grupos semejantes el conocimiento de lo real y avanzar sobre él. El desarrollo social constituye también el personal (Berger y Luckman 1968; Buber 1993). El propio desarrollo físico es por contacto con los demás (como la experiencia de los monos de Harlow). El desarrollo cognitivo también corre en paralelo al desarrollo social. Las investigaciones de Heckman están produciendo resultados de interés al evidenciar que los primeros años de vida son esenciales no sólo para el desarrollo cognitivo-motórico sino también para las habilidades sociales (Cunha y Heckman 2007; Cinha et al. 2006; Heckman et al. 2006; Heckman 2007).

\section{El hombre es proyecto, capaz de individualizarse y darse dinámicamente una identidad}

Las decisiones, que comportan renuncias, son las que van configurando la identidad del hombre. Algunas son conscientes y elegidas (ser esposo) otras son recibidas (ser hijo y ser hermano). Otras son inconscientes tal como muestran los estudios freudianos. Incluso hay «identidad» que es asignada por los demás y desconocida para el propio sujeto, si no se produce un acto de comunicación. En suma, el hombre - que en su naturaleza original fue creado como dueño del paraíso y situado en su centro- ha ido descubriendo que ni habita el centro del universo, ni es el centro de su propio destino, al menos de forma totalmente consciente. Esto le sitúa en una posición de labilidad (en el sentido de Ricoeur (2004) en Finitud y culpablidad), pero también capaz de simbolizar y de crear destinos com- 
partidos bajo relaciones sociales de inter-dependencia. Erik Erikson estudió las fases por las que el adolescente busca y logra su identidad en un proceso de «moratoria» entre la identidad heterónoma recibida de niño y la de mayor autonomía una vez concluida la moratoria. En ese proceso, es fundamental la información aportada por la «sociedad», por los demás que califican a la persona y aportan material para elaborar esa nueva identidad. De nuevo, el lenguaje y la sociedad se muestran indispensables. Un lenguaje que permite cooperar, trasmitir conocimiento, superar el simple estímulo-respuesta, organizar y dividir el trabajo y también amar y mentir. Dos experiencias humanas que son básicas: i) recibir y dar amor; ii) poder fallar y ser traicionado en ese amor. San Pablo lo expresará con fuerza en su «no hago el bien que quiero, más el mal que no quiero, eso hago» (Rom 7,19).

\section{El hombre, por su libertad, es capaz de autodeterminarse hacia el Bien}

Esa experiencia paulina común a todo hombre (sano) es fruto de haber sido creado libre. La libertad cristiana es una exigencia de haber sido creado por amor, a imagen y semejanza del Creador. Sin libertad no es posible recibir el amor, ni recrearlo «de vuelta». Este sentido de la libertad, funda el ser moral del hombre y es muy diferente al sentido de la antropología utilitarista-liberal de libre albedrío o, sobre todo, de ausencia de coacción. No está definida en un contexto relacional (libertad en función de que «los otros» no me coaccionen), sino en una ontología amorosa. Por haber sido creado y destinado por y al amor, es imprescindible haber sido creado y dejado libre, aunque eso suponga el riesgo del mal. Así, para la antropología cristiana, la ética es vivir en coherencia con esa experiencia creadora de amor. San Pablo desarrolla en Gal y Rom una reflexión de cómo la fe=acto libre de amor, conduce a la salvación. Y ser salvado es superar la Ley (que hace culpable), el sufrimiento (consecuencia de actos libres y de la finitud de la criatura) y la muerte, como último reducto de la experiencia común del mal. La libertad cristiana, entonces, es lo que posibilita descubrirse amado (hijo de Dios) y amar, como el acto libre más propio y 
«personalizante», pues persona es precisamente ser-en-relación. De nuevo la dimensión individual llama a la social. La institución primigenia del amor mutuo, base de la sociedad, es el matrimonio donde hombre y mujer -imprescindiblemente libres - se autodonan el uno al otro, se con-figuran y forman comunión. El matrimonio aparece así como la institución primordial donde se busca el bien común, no sólo desde una perspectiva cuantitativa o del tener, sino del ser, «ser parte de alguien» en una relación de recíproco don. La identidad personal pasa a configurarse «social». Se «es» con y para el otro, siendo la felicidad del otro el proyecto vital de cada uno de los cónyuges. Amar será buscar activamente el bien del otro dirá Aristóteles ${ }^{4}$.

En suma, la libertad se asienta en la base del amor que es valor supremo que configura las relaciones: identitarias (amor a uno mismo), fraternas (amor entre hermanos), filiales (amor a los padres que engendraron por amor), y trascendentales (amor al Dios que es Amor absoluto).

Crear instituciones sociales basadas en esta antropología que ha conducido a una ética es un desafío formidable, pero establece una idea de desarrollo humano completamente diferente a las tradicionalmente fijadas en economía, como veremos más adelante.

\section{El hombre trascendente: una realidad finita con deseo de infinito}

La dimensión trascendente del hombre no empieza con la fe. Se puede pensar la trascendencia desde la ontología y la metafísica. El arte, las experiencias de belleza o el culto a los difuntos son realidades humanas trascendentes que no exigen la fe. Una consecuencia importante de aceptar la trascendencia como característica propia del deseo de infinito (que mi vida no se acabe, seguir siendo recordado por los míos, aspirar a que no termine este momento de felicidad, etc.), es que genera esperanza e ilusión. Es decir, dinamiza fuerzas interiores que pueden conducir a obras concretas de ma-

\footnotetext{
${ }^{4}$ Aristóteles, Retórica, II, c.4, n. 2,1380b 35. Véase también Evangelii Gaudium del papa Francisco, 264-265.
} 
yor desarrollo que la simple aceptación de la finitud que se evidencia. En términos económicos, pensemos en lo que sería el emprendimiento empresarial o la inversión arriesgada sin esperanza. No se produciría. Es la capacidad de trascender el tiempo actual y proyectarse en un futuro mejor lo que enraíza muchos hechos económicos (claramente el ahorro y la inversión, como proyectos de consistencia inter-temporal). En epistemología agustiniana, será ese deseo de buscar la verdad o el fín último de las cosas (la cogitatio) lo que estará en la base del conocimiento ${ }^{5}$. El conocimiento empieza por la excitación que provoca la curiosidad. La ciencia será la capacidad de abstraer de la realidad la constancia de los efectos y deducir sus causas. Sin esa capacidad de trascender lo concreto, no es posible la ciencia ni la ética ${ }^{6}$. Aquí es donde se encuentra de nuevo la dimensión social que complementa la individual. Es la sociedad la que va mostrando al recién nacido los caminos hacia la «constancia de resultados» y la va troquelando como ser moral. «Siempre que tocas el fuego, te quemas y duele». Eso le permite predecir conductas y elegir de forma libre si toca el fuego o no. Las etapas del desarrollo moral de Piaget (1932) y Kohlberg (1958) tienen aquí un espacio de importancia por la secuenciación de la heteronomía a la autonomía moral.

Para el concepto de desarrollo esta distinción entre fines (poder ser más libre) y medios (crecimiento económico, redistribución de riquezas) será clave.

\footnotetext{
${ }^{5}$ Es la conocida referencia agustiniana del «nos hiciste Señor para Ti y nuestra alma permanece inquieta hasta que descanse en Ti». Las Confesiones, i, 1, 1. Es importante señalar cómo la propia epistemología agustiniana está basada en el amor, que diferencia entre caritas y cupiditas: «El amor dirigido al mundo por el mundo, la cupiditas, condena al ser humano a la más terrible de las infelicidades en la medida en que todo bien temporal se halla bajo la amenaza de su desaparición. Sólo la caritas, el amor a Dios por Dios y al prójimo por Dios, puede asegurar la verdadera felicidad en la posesión de un bien que no puede perderse por ser inmutable y eterno» (Ferrer y Roman, s.f.).

${ }^{6}$ Tampoco lo sería la ética al no poder generalizar principios, ni valores, ni actitudes. Otra cosa es que la valoración ética deba ceñirse a los actos concretos, mediados por las circunstancias e intenciones.
} 


\section{El hombre, ser cultural y consciente de su muerte}

El último dato de realidad antropológica que quiero resaltar es la consciencia del hombre de su final, de su muerte. Como animal que sabe que morirá, puede condicionar a ese dato muchas de sus decisiones, compromisos y actos. Además el saberse mortal suele reclamar una búsqueda del sentido de la existencia. Abocado inevitablemente a una cesación en el ser, busca qué sentido tiene precisamente "ser» y ser «así», humano, si esa existencia está marcada por la finitud. De nuevo la sociedad puede ayudarle a dar sentido a esa condición mortal. La convivencia en el amor con otros y para otros, puede «aliviar» el sentido de pérdida original frente al deseo de infinito comentado más arriba. Aunque la vida no sea eterna, puede desplegarse una existencia cargada de sentido. Cada cultura ha manejado este dato de realidad. De forma distinta, pero todas ellas han elaborado «narraciones de sentido» para el hecho de la muerte. La cristiana, como es sabido, se elabora en torno a la resurrección de Jesús por el Padre, plenificando su relación de amor. Todo fue creado por el Padre, para el Hijo, por amor (Espíritu Santo), según se afirma trinitariamente en el Credo cristiano.

En resumen, la antropología cristiana aporta dos datos que se han querido resaltar aquí: que el individuo es sociedad (persona es ser-en-relación) y que el amor es el valor subyacente sobre el que está construida toda esta antropología. Qué implicaciones tiene esta concepción de lo humano para el concepto de desarrollo económico es lo que se quiere expandir en el resto de este ensayo. Para ello, un primer paso, es profundizar, si quiera brevemente, sobre cómo se relacionó el fundador del cristianismo, Jesús, con la riqueza y la pobreza. 
III

\section{LAS RAÍCES BÍBLICAS: RIQUEZA Y POBREZA EN LA BIBLIA}

Aunque la tradición veterotestamentaria es rica en el desarrollo de la relación entre la riquezas y la bendición de Dios ${ }^{7}$, aquí nos centraremos en el aporte del Nuevo Testamento y más concretamente en las posturas de Jesús ante la pobreza y la riqueza.

La vida de Jesús se desarrolla sobre todo en Galilea y Judea, dos regiones muy diferentes en lo que a economía se refiere. Galilea es más rica en pesca y fertilidad agraria, mientras que Judea es más seca y pobre. Dentro de Galilea, Nazaret es una aldea pequeña que no destaca ni por su riqueza ni pobreza. Las dos decenas de sus habitantes se podrían clasificar como de «clase media». Si atendemos a la estructura social del tiempo de Jesús tal como la ha documentado Lenski (1966), la sociedad judía se dividía en nueve clases o estamentos con bajísima movilidad vertical entre ellas. Las cinco «superiores» eran la dirigente (terratenientes que controlaban las instituciones políticas a través de la política fiscal al ser los mayores contribuyentes); la clase gobernante, hereditaria que acumulaba el $25 \%$ de la producción nacional; los subalternos (escribas, burócratas y cargos públicos que no superaban el 5\% de la población) que mantenían buen nivel de ingresos pero carecían de poder político; los comerciantes o clase «bisagra» que solían mantener cierto estatus económico pero alejado de las superiores; la sacerdotal, que era la más baja de las «privilegiadas» a la vez que era terrateniente.

\footnotetext{
${ }^{7}$ Básicamente, el AT relaciona la bendición (beraca) de Dios con el hombre justo. El hombre que cumple la Torah será bendecido por Yahvé con una vida larga (muchos años), gran descendencia (muchos hijos), y grandes bienes materiales (mucha riqueza) como lo expresa Gn 24,35. Salomón será el paradigma de rey que ha sido bendecido con riquezas (1Re 3,13 y 10,10.21.27). El modelo entra en crisis a partir de la experiencia de la división del pueblo entre el Norte y el Sur y con el exilio de Babilonia. Ya en el Dt 6,10-12 se pone a la riqueza como el gran rival de Dios. Los sapienciales insistirán en que la explotación y el orgullo que traen la riqueza generan discriminación y engaño (Eclo 13,3-7 y 31,1-7; Miq 2,1-2; Am 6,4.6; Prov 30,7-9)La dramática obra de Job será una de las expresiones más directas de la quiebra de este modelo. Job es sucesivamente apartado de estas tres "recompensas" sin que tenga él conciencia de haber faltado a la Ley. Por eso la imagen de Dios fiel (hesed) queda puesta en entredicho, pero el desenlace del drama es el abandono de Job en la superior conciencia divina sobre el bien para cada hombre.
} 
Las cuatro clases inferiores, empobrecidas eran la campesina que practicaba el consumo de subsistencia y pagaba impuestos siendo la mayoría en número; los artesanos ( $5 \%$ de la población) en la que se situaba Jesús según la tradición y con menores ingresos que los campesinos; las clases impuras y degradadas (porteros, mineros, prostitutas), y la clase de los despreciables (5-10\% de la población) formada por delincuentes comunes, mendigos, subempleados itinerantes y cuantos se veían obligados a vivir de la caridad pública. Jesús, por tanto, se sitúa en la clase baja sólo por encima de impuros y despreciables y con menores ingresos que los campesinos. Como «obrero» (tektwn) e hijo de artesano (Mc 6,3 y Mt 13,55) carece de la seguridad que proporciona la posesión de tierras y vive dependiente de sus ingresos variables en función de su trabajo. Al igual que algunos de sus discípulos pescadores (Pedro, Andrés, Santiago y Juan) carecen de poder e influencia política, una de las dimensiones que hoy caracterizan la multidimensionalidad del desarrollo.

En su predicación, Jesús aborda de forma parca el tema de la riqueza. Los términos griegos polutos y jrêma (ambos para riqueza) aparecen en los sinópticos 5 veces y ninguna en Juan. Veamos de forma breve su tratamiento.

a) En Marcos el tema de la riqueza-pobreza aparece en tres pasajes. En Mc 4,18-19 se advierte del peligro de la riqueza al ser un «seductor» que hace ahogar el fruto de la palabra sembrada. Si en el Dt la riqueza era peligrosa por el orgullo que producía, desplazando a Dios del centro y sentido de la vida, Mc insiste en la seducción y las preocupaciones que traen consigo y que no permiten que la palabra de Dios germine en el corazón humano y engendre conductas evangélicas como la solidaridad con el desposeído, acogida al extranjero, la bendición y alabanza a Dios como primer mandato como respuesta a quien es el creador. En segundo lugar, en Mc 6,8-9 se hace referencia a la pobreza como el estilo de vida propio del discípulo enviado en misión. Como profeta itinerante de su tiempo, la pobreza externa será correlato y medio de credibilidad del anuncio, pues debe haber congruencia entre lo predicado y lo vivido. Sólo un bastón (defensa contra los asaltantes de caminos), pero ni pan, ni alforja, ni 
dinero. Una sola túnica y unas sandalias. Todo el mensaje conduce a la providencia y confianza en quien les envía. No hay seguridades a las que acogerse y la ligereza de equipaje permitirá el desplazamiento en misión. La pobreza será una muestra de que el predicador no busca su propio interés y por eso ha creado su propio discurso, sino que se es mensajero de otro que debe ser creído por el contenido de su mensaje, no porque su seguimiento proporcione "comodidades» que en aquél tiempo podrían ser ambicionadas por muchos.

Por último, Mc 10,17-31 presenta al hombre rico (no se dice que fuera joven, aunque es así conocido) que pregunta qué debe hacer para heredar vida eterna. Es sabido que la respuesta final de Jesús a la superior pregunta de «qué me falta» para el seguimiento fue vender cuanto tenía y dárselo a los pobres para poder seguir el propio estilo de vida adoptado por Jesús. El colofón de la tristeza que le produce al oyente será la exclamación de Jesús de lo difícil que es a los ricos entrar en el Reino de Dios. Vender, dar y seguir a otro (al Otro) es lo que acerca salvación. No es de extrañar que los propios discípulos de Jesús se sorprendieran y preguntarán «¿cómo podremos subsistir?» ${ }^{8}$. Desprenderse de la seguridad que proporciona acumular (frente a vender), tener (frente a dar) y seguir el propio deseo (frente seguirle a Él) será una enseñanza directa de que la salvación que trae Jesús es para esta vida (espiritual y material) y no una salvación para «la otra» vida. Es interesante caer en la cuenta que la versión de Mt añade en boca de Jesús las palabras del Lv 19,18 como mandato: «ama a tu prójimo como a ti mismo». El mandato es aquí concretado por el estilo de vida encarnado en Jesús, tanto en lo material como en lo moral.

b) Mt-posterior en datación a Mc- recoge lo aportado por su antecesor pero lo matiza y enriquece. Por centrarme en un aspecto clave, es en la colección de enseñanzas recogidas en el «sermón de la montaña» (bienaventuranzas) donde Mt expone la correcta actitud ante las riquezas 9 . La acumulación que merece la pena es

\footnotetext{
${ }^{8}$ O su equivalente «quién puede salvarse», según comenta Sicre (2013:275).

${ }^{9}$ Comentarios sin ningún análisis de las formas, contexto histórico, ni comentarios exegético-hermenéuticos teológicos conducen a afirmaciones como las de González
} 
la de Dios en el corazón (Mt 6, 19-21) pues allí no hay polilla ni carcoma que corroa. Se transmuta la tendencia natural a acumular para dirigir la riqueza a la experiencia de Dios como amor, tal como experimentó Jesús. Revertir la tendencia natural a invertir en «valores seguros de alta rentabilidad» se transmuta en invertir en "valores humanos de infinita dignidad», a través de acciones concretas como limosna, acogida hospitalaria, misericordia, perdón. La primera bienaventuranza, la de los pobres de espíritu (que Lc 6.20 deja en «pobres» sin más) se entiende mejor en el contexto axiológico de las demás: se alcanza dicha en la pobreza por ser consoladores, humildes, justos, compasivos, puros de corazón y pacíficos. Esta hermenéutica puede quedar reforzada por 1Tim 6,17-19 en la que Pablo recomienda a los ricos que no sean orgullosos poniendo su esperanza en el dinero, sino enriqueciéndose con buenas obras y con generosidad ${ }^{10}$.

En Mt 6,24 es donde aparece de forma clara que entre el dinero y Dios se establece una alternativa radical: no se puede servir a los dos, en línea con el primer mandamiento: amar a Dios sobre todo implica no tener otros dioses frente a mí, tal como experimentará el pueblo judío en su constante tentación a lo largo del éxodo. Cambiar la fe de la confianza en Dios, por la seguridad de los dioses visibles, especialmente si son de los ejércitos enemigos. La idolatría al dinero no consiste, por supuesto, en poner billetes en un pedestal y hacerles reverencias y plegarias (aunque con los de la lotería casi llega a estos extremos), sino en tres actitudes: injusticia directa (por fraude, robo o extorsión), injusticia indirecta (indiferencia ante el sufri-

\footnotetext{
Marsal (2013) que me parecen insostenibles y conducen a la presentación de Jesús como un liberal económico, incluso austriaco (defensor de la propiedad privada sin injerencia ni coacción, aprobación del contrato libre de obligado cumplimiento, libertad para establecer los salarios exclusivamente entre empleador y trabajador, desaprobación de la redistribución forzosa a través de los impuestos o exaltación de la empresarialidad). Una mejor fundamentación que por supuesto va mucho menos lejos es la de Rothbard (2013:61) que sitúa la actitud de Jesús y los primeros cristianos mediada por la expectación inminente del fin del mundo y el advenimiento del Reino de Dios.

${ }^{10}$ La generosidad judía se expresa mediante el ojo sano, frente al enfermo por tacañería.
} 
miento del pobre, como en la parábola de Lázaro y el rico Lc.16,19-31) y agobio que hace anteponer los bienes a la Providencia.

Este aspecto es importante y lo desarrolla Mt de forma extensa (Mt 6,25-34) pues la Providencia es un correlato transparente de la experiencia fundante en Jesús de Dios como Abbá, como Padre que se preocupa de sus hijos hasta el punto de conocer hasta los pelos de su cabeza. Un Dios que pide confianza absoluta en el acto de fe-salvación, se muestra como generosidad providente y absoluta en su revelación. El recuerdo al paraíso del Gn donde el hombre creado no poseía ninguna escasez bajo ese estado de naturaleza, se hace inevitable. Además, esa vivencia íntima de Jesús de Dios como Abbá, se traduce en la más material de las siete peticiones del Padrenuestro: el pan se pide y se concede a diario, no de una vez para siempre. No hay acumulación, porque en Dios no hay escasez ni discontinuidad. A cada día le basta su afán (Mt 6,34).

Por supuesto que la Providencia no exime del trabajo («el que no trabaja que no coma» 2Tes 3,10), ni de la redistribución concreta -en dinero y en especie- tal como hicieron los cristianos de Grecia con los de Jerusalén y que tanto empeño puso Pablo (2 Cor 8-9). No se «espiritualizó» la pobreza ni la solidaridad, sino que se practico una ayuda internacional para el desarrollo. Una de las mejores expresiones de este equilibrio entre providencia divina con acción humana comprometida es la expresión ignaciana: «trabaja como si todo dependiera de ti, sabiendo que todo depende de Dios» ${ }^{11}$. La primera comunidad cristiana materializa esta confianza «poniendo todos los bienes en común» (Hch 2,34-36), vendiendo lo que poseían, repartiendo según la necesidad de cada uno, de forma que no hubiera necesitados ${ }^{12}$.

${ }^{11}$ La cita es incierta. Benedicto XVI la refiere en el comentario del Ángelus de 17 de junio 2012 a Pedro de Ribadeneira, Vida de S. Ignacio de Loyola, Milán, 1998.

${ }^{12}$ El texto es «aspiracional» ya que el siguiente párrafo de Hch narra cómo José entregó lo conseguido por la venta de un campo, pero Ananías y Safira sólo entregaron una parte (Hch 5,1-10). Una interpretación quizá demasiado literal de este texto se encuentra en la base de ideas socialistas como las de Saint-Simon, Fourier o List en Francia y de Owen en Estados Unidos, intentando crear "comunidades ideales». Véase Escohotado (2013) cap.7. 
En resumen, Mt transmite dos posturas básicas: el valor relativo de los bienes materiales frente a absolutizar la fe en Dios providente y en su Reinado; y el valor absoluto de la persona necesitada que exige del prójimo la solidaridad concreta (frente a Caín, Jesús se vivió como el guardián de sus hermanos los hombres).

c) La aportación de Lc es varios aspectos original. Al incluir evangelio de la infancia, da pinceladas de que la pobreza fue una constante en la vida de Jesús: nace en un pesebre en la marginalidad de Belén, a su vez aldea marginal de Judea y por supuesto hiper-marginal en el imperio romano; los primeros adoradores son pastores (de la clase de los despreciables según la clasificación de Lenski), itinerantes; ya hemos mencionado que elimina el genitivo «de espíritu» en la bienaventuranza del pobre añadiendo una maldición explícita a los ricos (Lc 6,24); insiste en la necedad de acumular (Lc 12,13ss), denuncia la insolidaridad de muerte ante Lázaro (Lc16,19-31) y anima a actuar de forma inteligente como un administrador «injusto» (Lc 16,1-9). Pero Lc también modera la pobreza de Jesús. Le presenta con amigos ricos: Juana (Lc 8,3), José de Arimatea (23,20-53), Zaqueo (19,2-10). Jesús es un hombre culto en su tiempo al saber leer y escribir y posee una túnica de suficiente calidad como para no ser rasgada y dividida en partes por los romanos. Aunque llega a pasar hambre (Lc 6,1) y no tiene donde reclinar la cabeza (Lc 9,58), es recibido por Marta y María en Betania para descansar (Lc 10,38).

El libro de los Hch, del mismo autor, enfatiza — como ya hemos visto- la virtud del compartir, y señalan seguidoras de Jesús que son ricas en Tesalónica y Berea (Hch 17,4.12), aunque también las hay perseguidoras como las de Antioquía de Pisidia (Hch 13,50) o plateros ricos que cargan contra Pablo por destruir su negocio de venta de estatuillas (Hch19,24-29).

En resumen, la postura de Jesús ante la riqueza es de cautela ante los efectos que provoca en el corazón del hombre que le hacen posponer la relación de fe-confianza plena en Dios y su providencia, y la obligación moral de compartir y atender las necesidades de los prójimos (el Buen Samaritano Lc 10,25-37). Por otra parte, Jesús elige la pobreza (no extrema) como entorno de vida oculta y resalta que ésta ayuda a suscitar la fe y la confianza frente a la confianza en el dinero. La mayoría de sus amigos son po- 
bres, los signos-milagros se obran sobre marginados pobres y Jesús mantiene una relación social de preferencia hacia colectivos excluidos y sin poder: mujeres, enfermos, niños, ancianos, viudas, pecadores -incluidos los recaudadores de impuestos. La figura del anawim o pobre de Yahvé, aquél que espera salvación de Dios y no de sus fuerzas o méritos, será una clave hermenéutica para no hacer falsas separaciones materiales-espirituales sobre el valor de la pobreza. En la Biblia, ser pobre material es claramente un mal, lo mismo que una riqueza que se absolutiza y conduce a apoyarse en las propias fuerzas o a renegar de la necesidad de ser salvado por la fe en el Dios creador y providente.

\section{«DESARROLLO» EN LA DOCTRINA SOCIAL DE LA IGLESIA}

Es importante caer en la cuenta que la Biblia no es un libro de economía, ni de historia. No podemos acudir a ella para encontrar «recetas» de política económica, como no se debe buscar una explicación física sobre el origen del universo. Es más, Jesús parece tomar una actitud de indiferencia ante cuestiones económicas concretas. En Lc $12,12-14$, «uno de la multitud» le urge a Jesús a que diga a su hermano que reparta con él la herencia. La respuesta de Jesús fue parca a más no poder: «quién me ha puesto entre vosotros como juez o repartidor»?

Pero si la Biblia no debe ser la fuente de la praxis concreta en materia de vida económica o social, quizá lo podría ser el Magisterio de la Iglesia, que trata de profundizar e interpretar el depósito recibido por revelación bíblica. La Iglesia, en su Magisterio, atendiendo a los signos de los tiempos (GS 4 y 11) e interpretando de forma continua la revelación, tanto por las aportaciones de la teología como por el sentir del pueblo (LG12) ${ }^{13}$, trata de orientar la vida concreta de los

${ }^{13}$ La infalibilidad de los Pontífices cuando hablan ex-cátedra (LG 18) y la colegial de los Obispos (LG25: «pero manteniendo el vínculo de comunión entre sí y con el Sucesor de Pedro, convienen en un mismo parecer como maestros auténticos que exponen como definitiva una doctrina en las cosas de fe y de costumbres, en ese caso enuncian infaliblemente la doctrina de Cristo»), especialmente cuando están reunidos en Concilio ecuménico, se completa con la del Pueblo de Dios. Literalmente, «La uni- 
cristianos y de aquellos que quieren escuchar este mensaje. Respetando la autonomía de las ciencias y de la vida política-social-económica (GS 36) ${ }^{14}$, trata de ofrecer orientaciones morales tanto en el nivel de los principios como de las normas-costumbres.

La Doctrina Social de la Iglesia (DSI) es el corpus que estudia las realidades sociales ${ }^{15}$. En ella encontramos dos niveles de discurso: los principios orientadores (bien común, destino universal de los bienes, subsidiaridad y solidaridad) y los valores fundamentales (verdad, libertad, justicia y caridad) ${ }^{16}$.

Sobre los principios, es clarificadora la definición y relación entre ellos que realiza Benedicto XVI (2010):

Entre los principios indispensables para proporcionar un enfoque ético integral a la vida económica debe encontrarse la promoción del bien común, basado en el respeto de la dignidad del ser humano y principal objetivo de los sistemas de producción y del comercio, de las instituciones políticas y bienestar social. En nuestros días, la preocupación por el bien común ha adquirido una dimensión más marcadamente global. También es cada vez más evidente que el bien común abarca la responsabilidad hacia las futuras generaciones; la solidaridad entre generaciones a partir de ahora

versalidad de los fieles que tiene la unción del que es Santo (cfr. 1 Jn., 2, 20 y 27) no puede fallar en su creencia, y ejerce ésta su peculiar propiedad mediante el sentimiento sobrenatural de la fe de todo el pueblo, cuando "desde los Obispos hasta los últimos fieles seglares" manifiesta el asentimiento universal en las cosas de fe y de costumbres».

${ }^{14}$ Resalta el párrafo de no antagonismo en fe y razón: «La investigación metódica en todos los campos del saber, si está realizada de forma auténticamente científica y conforme a las normas morales, nunca será realmente contraria a la fe, porque las realidades profanas y las de la fe tienen origen en el mismo Dios».

15 Véase Camacho (1999) o Pontificio Consejo «Justicia y Paz» (2005).

${ }^{16}$ Que son semejantes a los que abren la Declaración del Milenio de Naciones Unidas (2000): libertad, igualdad, solidaridad, tolerancia, respeto de la naturaleza y responsabilidad común. Sobre la importancia de la responsabilidad y la educación en ella, carga de forma notable la Nota de la Santa Sede sobre la Financiación del Desarrollo en vísperas de la Conferencia de Doha: «ninguna intervención de regulación puede garantizar su eficacia prescindiendo de la conciencia moral bien formada y de la responsabilidad cotidiana de los operadores del mercado... La educación en la responsabilidad puede encontrar un fundamento sólido en algunos principios indicados por la doctrina social.... el bien común universal, el destino universal de los bienes y la prioridad del trabajo sobre el capital» (Pontificio Consejo «usticia y Paz» 2008). 
debe ser reconocida como un criterio ético fundamental para juzgar cualquier sistema social. Estas realidades apuntan a la urgencia de fortalecer los procedimientos de gobierno de la economía mundial, aunque con el debido respeto al principio de la subsidiariedad. Al final, sin embargo, todas las decisiones económicas y políticas deben estar encaminadas a «la caridad en la verdad», ya que la verdad preserva y canaliza la fuerza liberadora de la caridad en medio de las vicisitudes y las estructuras humanas, cada vez más contingentes. Pues «sin verdad, sin confianza y amor por lo que es verdadero, no hay conciencia social y responsabilidad, y la acción social termina sirviendo a los intereses privados y a las lógicas de poder, dando lugar a la fragmentación social».

No es el lugar de presentar la evolución de los mensajes sociales de los pontífices desde la Rerum Novarum de León XIII (1891) hasta la Caritas in Veritate de Benedicto XVI (2009) y la Evangelii Gaudium de Francisco (2013) que puede consultarse en amplias revisiones de la literatura (Camacho 1991, Pontificio Consejo Justicia y Paz 2005, Bestard Comas 2005, cap.V), pero sí merece la pena resaltar que el desarrollo ha sido el tema central de encíclicas como Mater et Magistra de Juan XXIII (1961) Populorum Progresio de Pablo VI (1967) y Sollicitudo Rei Sociallis de Juan Pablo II(1987). Caritas in Veritate de Benedicto XVI (2009) lleva precisamente como subtítulo «sobre el desarrollo humano integral en la caridad y en la verdad $»^{17}$.

Mater et Magistra utiliza casi siempre el término «desarrollo económico» (24 veces como recoge la Tabla 1 ) y se ocupa de los problemas «coyunturales» propios de su época: el desarrollo rural, la falta de empleo y dignidad de los trabajadores, la propiedad privada o la desigualdad entre países, siendo éste calificado como «el mayor problema de nuestros días» ${ }^{18}$.

${ }^{17}$ Para el origen y enlace con la tradición franciscana de la CV véase Zamagni (2010). Un comentario reciente con abundantes referencias a los antecedentes es el de Rubio de Urquía (2014).

${ }^{18}$ Impresiona la actualidad del n ${ }^{\circ} 157$ releído 53 años después: «Pero el problema tal vez mayor de nuestros días es el que atañe a las relaciones que deben darse entre las naciones económicamente desarrolladas y los países que están aún en vías de desarrollo económico: las primeras gozan de una vida cómoda; los segundos, en cambio, padecen durísima escasez. La solidaridad social que hoy día agrupa a todos los hombres en una única y sola familia impone a las naciones que disfrutan de abundante 
Populorum progressio es un hito fundamental en el tema y en ella se encuentra la formulación más acuñada de la concepción cristiana: «El desarrollo no se reduce al simple crecimiento económico. Para ser auténtico, el desarrollo ha de ser integral, es decir, debe promover a todos los hombres y a todo el hombre» (PP14) ${ }^{19}$, así como la vinculación estrecha y directa entre paz y desarrollo («desarrollo es el nuevo nombre de la paz» (PP87). Además ya es común utilizar la expresión "países (o pueblos) en vías de desarrollo» (hasta 7 veces). El sujeto «desarrollo» se adjetiva con «integral» $\left(n^{\circ} 5\right.$ y 14$)$, «humano» (6), «material» (12), «cultural» (12) o «personal» (16) y «mental» (45).

TABLA 1

RECUENTO DE TÉRMINOS SOBRE EL DESARROLLO EN CINCO DOCUMENTOS DE LA DSI

\begin{tabular}{|c|c|}
\hline Encíclica & Veces que aparece «desarrollo» \\
\hline Mater et Magistra (1961) & 24 (desarrollo económico) \\
\hline Populorum Progressio (1967) & 60 (desarrollo integral, desarrollo humano) \\
\hline Sollicitudo Rei Socialis (1987) & 146 (auténtico desarrollo) \\
\hline Caritas in Veritate (2009) & 229 (desarrollo humano integral: 16 veces) \\
\hline Evangelii Gaudium (2013) & 16 (desarrollo integral) \\
\hline
\end{tabular}

Nota: el recuento sólo considera el término en el cuerpo del texto, no en los títulos ni subtítulos. Fuente: elaboración propia.

riqueza económica la obligación de no permanecer indiferentes ante los países cuyos miembros, oprimidos por innumerables dificultades interiores, se ven extenuados por la miseria y el hambre y no disfrutan, como es debido, de los derechos fundamentales del hombre. Esta obligación se ve aumentada por el hecho de que, dada la interdependencia progresiva que actualmente sienten los pueblos, no es ya posible que reine entre ellos una paz duradera y fecunda si las diferencias económicas y sociales entre ellos resultan excesivas» (MM 157).

19 A continuación cita «Nosotros no aceptamos la separación entre lo económico y lo humano, ni entre el desarrollo y la civilización en que se halla inserto. Para nosotros es el hombre lo que cuenta, cada hombre, todo grupo de hombres, hasta comprender la humanidad entera» de L. J. Lebret. O. P., Dynamique concrete du développement (Paris, Economie et Humanisme, Les Editions Ouvrieres, 1961) pág. 28, que es un ejemplo de cómo la reflexión laica del desarrollo enriquece la teología y el magisterio pontificio en armonía de razón y fe. 
Por su parte, Sollicitudo Rei Socialis escrita a los 20 años de PP, puede considerarse como la primera encíclica que aborda de manera central la cuestión del desarrollo. Aparece 146 veces en el texto, en prácticamente todos sus números. Utiliza nuevos adjetivos como «auténtico» desarrollo humano, desarrollo (también) espiritual y humano, basado en los Derechos Humanos (SRS 15), «verdadero e integral del hombre y de los pueblos» (SRS 21).

Pero es en Caritas in Veritate donde el concepto de «desarrollo humano integral» (16 veces) toma fuerza en el documento que más veces menciona el término desarrollo (229, es decir en casi todos los números al menos una vez y en varios de ellos muchas veces ${ }^{20}$. Con la intención de celebrar el 40 aniversario de la PP, una de sus principales novedades es la propuesta de abrir el desarrollo humano integral - considerado como una vocación —respuesta del hombre al Dios creador- ( $\mathrm{n}^{\circ}$ 11) a la «lógica del don» que se funda en el amor de caridad ${ }^{21}$ — que es Dios mismo, para los cristianosy que incorpora los valores de la fraternidad, justicia y gratuidad en una armonía desconocida hasta entonces.

Por último, la reciente Exhortación apostólica de Francisco, Evangelii Gaudium, continua la tendencia del uso del término «desarrollo integral» (16 veces), aunque eludiendo explícitamente que no en su espíritu - el adjetivo «humano».

\footnotetext{
${ }^{20}$ Hasta 11 veces en el número 18 y 7 veces en los números 11,17,21,29 y 68 .

${ }^{21}$ «La comunidad humana puede ser organizada por nosotros mismos, pero nunca podrá ser sólo con sus propias fuerzas una comunidad plenamente fraterna ni aspirar a superar las fronteras, o convertirse en una comunidad universal. La unidad del género humano, la comunión fraterna más allá de toda división, nace de la palabra de Dios-Amor que nos convoca. Al afrontar esta cuestión decisiva, hemos de precisar, por un lado, que la lógica del don no excluye la justicia ni se yuxtapone a ella como un añadido externo en un segundo momento y, por otro, que el desarrollo económico, social y político necesita, si quiere ser auténticamente humano, dar espacio al principio de gratuidad como expresión de fraternidad». (CV 34). Véase el comentario del Consejo de Redacción de Revista de Fomento Social (2010) y el de Pancorbo (2011).
} 


\section{$\mathrm{V}$ \\ DIÁLOGO CON EL CONCEPTO DEL PNUD Y LA ESCUELA AUSTRIACA}

Es ilustrativo el análisis comparativo que realiza Bestard (2003) al comparar los Informes sobre el Desarrollo Humano del PNUD y los documentos de la DSI. Encuentra nueve coincidencias notables y una diferencia. Las concordancias son:

a) una visión negativa del desarrollo en las décadas de los ochenta y noventa (sobre todo en la SRS de Juan Pablo II);

b) la clara superación de que el desarrollo es más que crecimiento económico;

c) el énfasis en que el auténtico desarrollo debe ser participativo y el papel clave que juegan las organizaciones de la sociedad civil;

d) una viva preocupación por el desempleo como freno al desarrollo;

f) el largo camino que resta hasta que se produzca una verdadera igualdad entre los sexos;

g) el armamento, la guerra y conflictos como enemigos del desarrollo;

h) el convencimiento de que el libre mercado no garantiza por sí mismo una distribución justa de los bienes ni de las oportunidades;

i) la gravedad del problema que supone el sobreendeudamiento externo;

j) la común visión de la globalización como fuente de oportunidades pero también de amenazas;

la discrepancia mayor se concreta en el problema demográfico.

Para el PNUD (1999) ${ }^{22}$, el desarrollo es un concepto multidimensional, integral: «Aumentar las opciones de la gente, (oportunidades), para vivir una vida digna y saludable (sanidad), adquirir conocimientos (educación), tener acceso a los recursos necesarios para un nivel de vida decente (renta), mientras se preserva para las generaciones futuras, (sostenible), se garantiza la seguridad hu-

${ }^{22}$ Para la evolución de las distintas formas de definir desarrollo humano en los Informes de Desarrollo Humano, véase Alkire (2010). 
mana (paz) y se logra la igualdad de las mujeres y los hombres (género)».

La diferencia con la concepción de la DSI es que ésta no entiende por integral las variadas dimensiones, sino el hombre completo (todo el hombre), enfatizando que debe incorporar la dimensión trascendente. Tal como se vio en la segunda sección, la antropología cristiana defiende al hombre como ser con vocación de infinito, capaz de elevarse por encima de la realidad concreta (que su razón le aporta) gracias a su ser capaz de trascenderla (conocimiento por la fe, complementaria a la razón).

Uno de los inspiradores del concepto de desarrollo humano, A.K. Sen (2000), a través de su enfoque de capacidades, titularidades y oportunidades, define el desarrollo como el proceso de expansión de las libertades reales que disfrutan los individuos. «Es ofrecer las oportunidades para aumentar las capacidades de los individuos, de forma que puedan vivir el tipo de vida que tienen razones para valorar». Las cinco libertades fundamentales que garantizan un proceso de desarrollo humano son libertades políticas, servicios económicos, oportunidades sociales, garantías de transparencia y seguridad protectora. Si bien hay que reconocerle el mérito de plantear el desarrollo como libertades, Sen no termina por «aterrizar» ni una antropología ni una ética concretas. Se limita a reconocer la diversidad de «razones» por las que los individuos valoran su proyecto de vida como valioso, pero no concreta esos valores ni pretende una ética objetiva o compartida a nivel global. Ya hemos visto como la DSI sí lo hace. Propone a «los hombre de buena voluntad» su visión del hombre recibida en la vida y mensaje de Jesús y su reflexión ética nacida a partir de la buena noticia de la salvación en ese Jesús. Es precisamente el amor de caridad que Jesús vivió e invitó a vivir a sus seguidores, lo que diferencia la concepción cristiana del desarrollo. Un concepto de amor tan novedoso que los autores del Nuevo Testamento buscaron en el término griego agape como el que mejor podría expresar lo recibido, a diferencia del amor de amistad (filía) o el amor romántico o propio ${ }^{23}$ (eros). Este fundamento del amor del

${ }^{23}$ Sobre el amor propio como substrato de una ética, véase Savater (1988), Schwartz y Martín (1991), Conill (1996). En el diálogo de la moral católica y el liber- 
que busca activamente el bien para el otro (amado) por considerarlo su hermano (fraternidad), nace de la experiencia previa de saberse original e incondicionalmente amado por el Ser-Amor supremo, el Dios de Jesús. No es, además, un concepto revelado sobre el que no se pueda reflexionar filosóficamente. Gómez Caffarena construye en torno a él, gran parte de su metafísica ${ }^{24}$. Para el jesuita, el amor de agape es lo que fundamenta la libertad.

$\mathrm{Y}$ aquí se abre una brecha notable entre la libertad entendida por los liberales y la cristiana. Para los liberales, el fundamento antropológico de la actividad social es el individuo y la regla moral más concisa será la que Hume sintetice en: i) estabilidad en la posesión, ii) transferencia por consentimiento y iii) cumplimiento de las promesas. Autores liberales (Schwartz 1994:131) asientan las relaciones sociales en estos tres principios: respeto a la propiedad privada, libertad de cumplimiento de los contratos, no interferencia en los precios libremente formados. La distancia entre los de la DSI parece evidente, pues las éticas liberales tratan de basar la ética fuera de toda noción de Dios y de naturaleza, mientras que las cristianas parten precisamente de ellas: revelación del Dios personal en Jesús y ley natural. El hombre pierde con el pecado (original) el estado de naturaleza donde conoce y diferencia el bien y el $\mathrm{mal}^{25}$. En su estado de naturaleza caída (y redimida en Jesús), ese conocimiento se ha oscurecido. De ahí la enorme dificultad práctica de actuar bajo el principio de fraternidad universal, observar de forma concreta una «hipoteca social» sobre los bienes (reconociendo la posibilidad y existencia de los bienes comunes o de propiedad común, tal como recoge la Declaración Universal de los Derechos Humanos, art. 1726), o ejercer políticas de «desarrollo» realmente orientadas por el principio de solidaridad. Al ser este «la determinación firme y perseverante de empeñarse por el bien común, es decir, por el bien de todos y de cada uno, para que todos

\footnotetext{
alismo me ha inspirado también Hidalgo (2011).

${ }^{24}$ Véase Gómez Caffarena (1983), cap.IX titulado precisamente «Amor». Y no es casualidad que sea el capítulo anterior al dedicado a la libertad.

${ }^{25}$ Para un desarrollo de estos principios y su conexión con la filosofía tomista y de la Escuela Austriaca, véase Zanotti (2011).

26 «Toda persona tiene derecho a la propiedad, individual y colectivamente. Nadie será privado arbitrariamente de su propiedad».
} 
seamos responsables de todos» (SRS 38) se ve claramente su conexión con el concepto de desarrollo integral de la PP y de cómo esta «virtud social» (Pontificio Consejo Justicia y Paz 2005, nº193) es, en el fondo, el concepto de amor ya comentado: la búsqueda activa del bien común que presupone un acto libre. La libertad cristiana es un don que se recibe por haber sido creado por Amor y destinado al Amor. Es un don dinámico (una variable flujo, diríamos los economistas) que se conquista a lo largo de toda la vida mediante las acciones libres y responsables. Ser libre es ser capaz de autodirigirse hacia el bien. Un bien que es comunicado por Dios a la conciencia recta del hombre (Gaudium et Spes [GS] 16). Completamente diferente es la noción liberal de libertad como ausencia de coacción. El cristiano, al amar, tiende naturalmente a expandir ese bien recibido. El liberal, procura defenderse de toda forma de coacción ajena, absolutizando de alguna forma la «libertad de» (libre albedrío y ausencia de coacción) frente a la «libertad para» (orientarse teleológicamente hacia un proyecto de vida buena) que diferenciaron los escolásticos ${ }^{27}$.

En resumen, hasta aquí hemos presentado coincidencias múltiples entre el concepto de desarrollo humano de Naciones Unidas y de A.K. Sen, aunque también diferencias debidas a «alcances» diversos. La DSI extiende el horizonte de conocimiento y del ser hu-

${ }^{27}$ Esta diferenciación se profundiza en Gómez Caffarena (1983) cap.X. No es que haya una oposición frontal entre la libertad «liberal» y como la entiende la DSI. En la GS 17 se dice: «La orientación del hombre hacia el bien sólo se logra con el uso de la libertad, la cual posee un valor que nuestros contemporáneos ensalzan con entusiasmo. Y con toda razón. Con frecuencia, sin embargo, la fomentan de forma depravada, como si fuera pura licencia para hacer cualquier cosa, con tal que deleite, aunque sea mala. La verdadera libertad es signo eminente de la imagen divina en el hombre. Dios ha querido dejar al hombre en manos de su propia decisión para que así busque espontáneamente a su Creador y, adhiriéndose libremente a éste, alcance la plena y bienaventurada perfección. La dignidad humana requiere, por tanto, que el hombre actúe según su conciencia y libre elección, es decir, movido e inducido por convicción interna personal y no bajo la presión de un ciego impulso interior o de la mera coacción externa. El hombre logra esta dignidad cuando, liberado totalmente de la cautividad de las pasiones, tiende a su fin con la libre elección del bien y se procura medios adecuados para ello con eficacia y esfuerzo crecientes. La libertad humana, herida por el pecado, para dar la máxima eficacia a esta ordenación a Dios, ha de apoyarse necesariamente en la gracia de Dios. Cada cual tendrá que dar cuanta de su vida ante el tribunal de Dios según la conducta buena o mala que haya observado». 
mano hasta la trascendencia y la revelación del Dios-Amor, que salva y por tanto invita a actuar basándose en unos principios morales-sociales más amplios. Actuar de forma activa buscando compartir ese amor porque ese amor ha hecho hijo al «individuo» liberal y hermanos a la comunidad de hijos (fraternidad).

¿Cómo plantea la Escuela Austriaca esta visión del desarrollo? Obviamente el plano de diálogo se establece en la epistemología y antropología que subyace a estos autores.

En primer lugar puede sorprender la elección de la Escuela Austriaca (EA) de economía para un diálogo con la DSI y un concepto de desarrollo humano. En efecto, esta escuela de pensamiento puede considerarse «marginal» en la teoría económica «convencional» (neoclásica) o en los manuales de pensamiento económico (Blaug 1985) ${ }^{28}$, aunque dos de ellos, el de Schumpeter (2012) ${ }^{29}$ y el de Rothbard (2013) son considerados autores austriacos. Es más, ningún autor austriaco importante aparece en los manuales de historia del pensamiento sobre el desarrollo (Meiers \& Seers 1984; Bustelo 1998; Hidalgo 1998, 2011; KS \& Reinert 2005; KS 2005). Estos manuales suelen clasificar a los autores en torno a su postura sobre el papel e importancia del Estado en la actividad económica y el proceso de desarrollo. Precisamente los austriacos serán los autores que más critiquen el socialismo (Mises 2009) y la economía de planificación central (Hayek 1978, 1990, 1991, 2011). Quizá por eso, por su énfasis en la libertad y el subjetivismo metodológico, junto con su opción metodológica por el hipotético-deductivo y desprecio a toda la tradición empirista en economía (hoy podríamos denominarlo el «econometricismo»), no ocupen casi ningún lugar en los estudios del desarrollo. La asignación austriaca es un buen ejemplo de cómo las «etiquetas» confunden. Para la «ortodoxia» neoclásica (o monetarista), los austriacos son heterodoxos,

${ }^{28}$ La única referencia austriaca en este manual es a la teoría del interés de BöhnBawerk a la que dedica 10 páginas de las más de 800 que tiene el manual. Ni siquiera aparecen Menger, Mises o Hayek. Blaug fue un férreo defensor de la economía y antropología neoclásica hasta su reciente reconocimiento de que es muy superior la austriaca. Véase Huerta de Soto (2004) nota 34, p.35.

29 Schumpeter, aunque de origen geográfico austriaco, no suele ser calificado como autor de la escuela austriaca pero fue alumno de Böhn-Bawerk, uno de sus fundadores. 
pero para los intervencionistas o socialistas defensores del desarrollo, serían una rama extraña de «liberales» o «neoliberales» y extrema en sus autores «anarco-capitalistas» (Rothbard).

No obstante, parece existir un reconocimiento de que los autores religiosos católicos de la Escuela de Salamanca son un antecedente la EA (Huerta de Soto 2011); hay una coincidencia temporal clara entre la DSI que nace con la Rerum Novarum (1891) y se despliega a lo largo del todo el siglo XX abordando cuestiones como la condena al marxismo (y a cierto capitalismo en la Centessimus Annus 1991) ${ }^{30}$ que comparten Böhn-Bawerk y Hayek y al totalitarismo nazi que sufrió Mises. Un austriaco reconocido es Gabriel Zanotti $(2011 a, b)$ que construye su metodología económica sobre la base de un neotomismo católico para nada oculto y, por ejemplo, el capítulo IX de La fatal arrogancia de Hayek (1991) —un agnóstico declarado- está dedicado expresamente al papel de la religión sobre la que reconoce el papel de "preservar las costumbres benéficas» (Hayek 1991:215) al tiempo que ve imposible la construcción racional de una ética universal. Sin embargo para él, las únicas religiones que han sobrevivido han sido las que han defendido «la familia y la propiedad plural» (p.214). Si sustituimos propiedad plural por bien común, la coincidencia con dos de los fundamentos sociales católicos es muy notable. Por otra parte, la revista de economía austriaca en español Procesos de Mercado ofrece varios artículos en diálogo con la DSI y la religión (Hidalgo 2011, Pancorbo 2011, González Marsal 2013).

El diálogo entre la EA y el pensamiento cristiano y la DSI puede ser muy fecundo y extenso. De entrada, debería diferenciarse del

${ }^{30}$ Véanse las coincidencias y diferencias con el liberalismo en Calvez (1992) o Rodríguez Braun (2011) y las referencias críticas al capitalismo en CA 33, 35 y 42 . Este último número afirma: «Si por "capitalismo" se entiende un sistema económico que reconoce el papel fundamental y positivo de la empresa, del mercado, de la propiedad privada y de la consiguiente responsabilidad para con los medios de producción, de la libre creatividad humana en el sector de la economía, la respuesta ciertamente es positiva, aunque quizá sería más apropiado hablar de "economía de empresa", "economía de mercado", o simplemente de "economía libre". Pero si por "capitalismo" se entiende un sistema en el cual la libertad, en el ámbito económico, no está encuadrada en un sólido contexto jurídico que la ponga al servicio de la libertad humana integral y la considere como una particular dimensión de la misma, cuyo centro es ético y religioso, entonces la respuesta es absolutamente negativa». 
diálogo entre el liberalismo y el pensamiento social cristiano. Una revisión de la postura de los Papas ante el liberalismo se ofrece en el Anexo. Aquí sólo deseo resaltar algunas coincidencias y diferencias que me parecen de interés por su relación con el concepto y proceso de desarrollo humano.

a) Su celo por la libertad, el «mercado libre» ${ }^{31}$, que se expresa en su concepto de "orden espontáneo», la idea de desarrollo como libertades de A.K. Sen y la necesidad de ser libre para amar-ser amado de los cristianos. Los austriacos enfatizan que el hombre es «ignorante» de todos los medios y fines que cada persona va seleccionando y realizando a lo largo de su vida. Como la información y el conocimiento es siempre limitado y disperso, no hay posibilidad de planificación y por tanto lo mejor es dejar a los sujetos realizar contratos libres bajo el derecho fundamental del respeto a la propiedad privada. Ya hemos expuesto cómo la DSI condiciona este derecho al destino universal de los bienes, existiendo una «hipoteca social» sobre las posesiones del individuo. Además su libertad puede estar «cautiva», "ciega». No siempre sabe lo que quiere y es bueno para él ${ }^{32}$. Para la Iglesia, no se es «dueño» de los bienes sino «administrador» para lograr el fin último de la vida: conocer el Amor originario, dejarse amar por Dios, amarlo y amar a los semejantes en fraternidad, incluidos los enemigos. La Iglesia católica podría crecer en el diálogo con los austriacos repensando lo que hay de uniformidad en ella y que limita la creatividad del «orden espontáneo» en distintas comunidades: liturgias, formas de organizar el gobierno (servicio) pastoral y de la caridad, etc.

${ }^{31}$ Nótese que el sustantivo es mercado y libre adjetivo, frente a la opción opuesta de «libre mercado».

32 «La dignidad humana requiere, por tanto, que el hombre actúe según su conciencia y libre elección, es decir, movido por e inducido por convicción interna personal y no bajo la presión de un ciego impulso interior o de la mera coacción externa. El hombre logra esta dignidad cuando, liberado totalmente de la cautividad de las pasiones, tiende a su fin con la libre elección del bien y se procura medios adecuados para ello con eficacia y esfuerzo crecientes. La libertad humana, herida por el pecado, ... ha de apoyarse necesariamente en la gracia de Dios» (GS 17). 
b) La preocupación metodológica: contra el neo-positivismo (y el «econometricismo») y la reducción de la acción humana a la estadística y medición, podría enlazar con «El método en Teología» de Lonergan (1994) (experimentar-> entender -> juzgar -> decidir), un aspecto demasiado complejo y amplio para discutir aquí. Pero sí es cierto que la preocupación austriaca por fundamentar la economía en la praxeología ${ }^{33}$, le ha llevado a un enfoque amplio de ciencias sociales que en todo caso incluye la ética y la axiología. También es cierto que hay una notable diferencia entre el individuo que elige fines bajo información dispersa y la trascendencia cristiana que le concibe como Imago Dei.

c) El individualismo ontológico utilitarista neoclásico es sustituido por el individualismo metodológico y subjetivo, que permite mayor apertura a hechos humanos. Hayek parece tener una concepción del individuo como ser-social que es la base del personalismo cristiano. La oposición frontal al «cálculo económico» así como la construcción miseana de la «acción humana» contra el «equilibrismo» de Walras, hace que el diálogo economía-DSI sea más cercano y fecundo con los austriacos que con los utilitaristas neoclásicos (Bentham o Jevons, entre otros).

d) La lucha contra el totalitarismo comunista y el socialismo (histórico en los Papas y en Mises-Hayek) es también un punto en común, aunque la Iglesia se centre en su condena al marxismo por ser ateo y no por su «arrogante» - parafraseando a Hayeksistema planificador. El principio de subsidiariedad estaría en frente de la planificación central (Zanotti 2011:88-91 aplica este principio a las externalidades, los bienes públicos y la redistribución). Hayek mismo admite que los gobiernos municipales redistribuyan ciertos bienes públicos, citando expresamente el principio de subsidiariedad de la DSI (Hayek 1978 vol.II, cap.7) ${ }^{34}$.

${ }^{33}$ La economía es praxeológica al interesarse por las acciones humanas y estudiar cómo se ajustan a principios generales y abstractos. Mises es el padre de la praxeología, mientras Hayek denomina catalaxia al estudio del orden de mercado. Rubio de Urquía (2014:190) define la DSI precisamente como el Corpus de enseñanzas «acerca de la dinámica global de la acción humana».

${ }^{34}$ «La subsidiariedad es, ante todo, una ayuda a la persona, a través de la autonomía de los cuerpos intermedios. Dicha ayuda se ofrece cuando la persona y los sujetos sociales no son capaces de valerse de por í mismos, implicando siempre una finalidad 
e) Una diferencia significativa es que los austriacos ponen un gran acento antropológico en la capacidad creativa y de «estar alerta» ante las oportunidades que generan los fines de las personas y la búsqueda de sus medios para logralos por parte de los empresarios. La empresarialidad será la clave contra la pobreza ${ }^{35}$. La DSI, sin embargo, que puso más empeño en la defensa del obrero, del trabajador, siendo esa «cuestión social» la originante del pensamiento en Rerum Novarum —ha ido reconociendo la importancia clave de la iniciativa empresarial pues «ser empresario, antes de tener un significado profesional, tiene un significado humano» (CV 41 y véase también CV 46 o Novak 1993).

f) Otra diferencia es la consideración de la justicia. Mientras que para los austriacos esta es conmutativa (justo es lo que acuerdan las partes sin coacción, engaño, fraude o violencia) o legal-distributiva, ya que esta es la necesaria para el funcionamiento del orden de mercado, la DSI utiliza más acepciones. En primer lugar es una actitud «determinada por la voluntad de reconocer al otro como persona» (justicia subjetiva) (Pontificio Consejo Justicia y Paz 2005:103). Considera también una justicia natural como el deber de dar a cada trabajador lo necesario para cubrir sus necesidades básicas. Salario justo es aquél que permite cubrir las necesidades del trabajador y su familia (GS 67) ${ }^{36}$. Además, la DSI utiliza con amplitud la justicia social precisamente como principio rector del orden económico y expresamente negada por Hayek (1978, vol. II). En las relaciones entre individuos, ambos coinciden en el respeto a la propiedad privada

emancipadora, porque favorece la libertad y la participación a la hora de asumir responsabilidades... es al antídoto más eficaz contra cualquier forma de paternalismo» (CV 57). «El principio de subsidiariedad debe mantenerse íntimamente unido al de solidaridad y viceversa, porque así como la subsidiariedad sin sin la solidaridad desemboca en el particularismo social... la solidaridad sin la subsidiariedad acabaría en el asistencialismo que humilla al necesitado» (CV58). La cursiva es propia.

${ }^{35}$ Véase en este sentido el sitio www.povertycure.org para una orientación austriaca del desarrollo.

${ }^{36}$ La postura es idéntica a la de la Declaración Universal de los DD.HH. art.23.3 «toda persona que trabaja tiene derecho a una remuneración equitativa y satisfactoria, que le asegure, así como a su familia, una existencia conforme a la dignidad humana y que será completada, en caso necesario, por cualesquiera otros medios de protección social». Véase Pontificio Consejo Justicia y Paz 2005, nº 302. 
(pero la DSI bajo «hipoteca social») y se diferencian plenamente en los derechos sociales (educación, sanidad, trabajo, salario justo, seguridad social, cultural) que garantizan una protección social básica. Por último, la DSI también considera la justicia internacional en las relaciones entre países. «Procurar el desarrollo de todos los hombres responde a una exigencia de justicia a escala mundial, que pueda garantizar la paz planetaria y hacer posible la realización de un humanismo pleno gobernado por los valores espirituales» (Pontificio Consejo Justicia y Paz 2005:52). Por ejemplo, la DSI admitiría el principio de injerencia en la soberanía nacional cuando existe una crisis humanitaria que cuestiona la supervivencia de un pueblo. Se reconoce a «la comunidad internacional» como capaz de administrar la justicia supra-nacional (La Haya o Ginebra, por ejemplo). Por último, los austriacos no reconocen injusticia en las circunstancias de nacimiento. Sólo es justo lo que surge de la competencia libre que es la que permite conocer realmente los precios y remuneraciones. El esfuerzo hacia planes no requeridos por personas será esfuerzo improductivo. Y el precio de los bienes es el valor subjetivo atribuido por cada individuo. De esta forma, como no hay organización social fuera de la legal, no es necesario intervenir a favor de la llamada «justicia social». Obviamente, la desigualdad material (y de oportunidades debida a las circunstancias al nacer, los «tipos» en el lenguaje de Roemer 1993, 2013), carecen de interés para estos autore ${ }^{37}$. Tal como expresa Benedicto XVI, «El amor —caritas - siempre será necesario, incluso en la sociedad más justa. No hay orden estatal, por justo que sea, que haga superfluo el servicio del amor. Quien intenta desentenderse del amor se dispone a desentenderse del hombre en cuanto hombre» (Deus Caritas Est 28b); «la caridad supone y completa la justicia según la lógica de la entrega y el perdón... $\mathrm{La}$ "ciudad del hombre" no se promueve solo con relaciones de

${ }^{37}$ Para la DSI sin embargo, ésta es esencial para un correcto y humano funcionamiento del mercado y la empresarialidad: «sin la solidaridad es que todos se sientan responsables de todos; por eso no se la pude dejar solamente en manos del Estado..., sin la gratuidad no se alcanza ni siquiera la justicia. Se requiere, por lo tanto, un mercado en el cual puedan operar libremente, con igualdad de oportunidades, empresas que persiguen fines institucionales diversos» (CV 38). 
derechos y deberes, sino antes y más aún, con relaciones de gratuidad, de misericordia y de comunión» (CV 6).

g) Para los austriacos, la cooperación es un resultado de actos individuales libres. No debe hacerse ayuda internacional ya que no es posible conocer verdaderamente las necesidades y valoraciones de los supuestos «beneficiarios», tal como defiende Bauer (1972). Claramente, lo más contrario a un austriaco es hacer cooperación bajo «marcos lógicos» que «arrogantemente» pretenden saber las valoraciones y fines de vida de los ayudados sin darse cuenta de que esos fines pueden cambiar constantemente debido precisamente a su libertad. Esta línea argumental de crítica hacia la ayuda externa oficial (entre gobiernos) es en la actualidad expuesta y defendida por Easterly $(2008,2014)$ quien resalta la inexistencia de conocimiento «experto» ni de expertos que hayan podido realmente ser eficaces en la labor antipobreza. La DSI por el contrario considera un deber propio del hombre la ayuda mutua ${ }^{38}$ ya que la humanidad es considerada una fraternidad de hijos de Dios creados para el amor. El pecado de Caín al envidiar a su hermano y no reconocerse como hijo amado condujo a preguntar si era guardián de su hermano. La respuesta vino con la vida y muerte de Jesús que evidenció un «sí» alto y claro.

En resumen, en el plano antropológico existen coincidencias entre la DSI y la idea de hombre de los austriacos, su método de construcción de conocimiento económico y social y los valores primordiales que toda sociedad debe promover. Pero también existen marcadas diferencias. Es cierto que algunas se deben a que la DSI realiza un camino de «vuelta» en el conocimiento (el teológico o

38 «No se puede confiar el desarrollo ni al solo proceso casi mecánico de la acción económica de los individuos, ni a la sola decisión de la autoridad pública» (GS 65). En CV 41 se defiende la ayuda al desarrollo; en el 47 Benedicto XVI critica a las Instituciones Financieras Internacionales por «mantener costosos organismos burocráticos, que destinan a la propia conservación un porcentaje demasiado elevado de esos recursos que deberían ser destinados al desarrollo; y en CV 58, se sostiene que las ayudas internacionales al desarrollo deben: evitar dependencia; no perseguir otros fines; implicar a los agentes sociales no sólo a los gobiernos; que los programas sean integrados y compartidos desde la base». 
Teología Fidei según Santo Tomás, siendo «la ida» el filosófico o Teología Natural) y que eso supone un plano diferente de conocimiento, que - siendo razonable - no es racional. Pero eso no debería privar del necesario diálogo. La caridad que para los creyentes es el Amor de Dios recibido, recogido y que debe ser reflejado en un compromiso que se concreta en una opción preferencial por los pobres, puede enriquecer la praxeología austriaca. Lejos de interpretarse como paternalismo, la caridad, que debe ser la impronta característica del obrar social cristiano, tal como expone Benedicto XVI (Deus Caritas Est 32), puede ser pensada a la luz de los «órdenes espontáneos» surgidos de las interacciones e intercambios libres de aquellos que se aman.

VI

CONCLUSIONES.

La relación entre desarrollo y religión no ha sido fácil (Selinger 2004) aunque actualmente existe cierto movimiento para recuperarla y repensarla (Carbonnier 2013). En este trabajo hemos tratado de poner en diálogo el pensamiento antropológico y social de la DSI con el enfoque de «desarrollo humano» de Naciones Unidas y la escuela austriaca. Su preocupación por concebir un desarrollo «con rostro humano» (Cornia et al. 1987) junto a la idea de desarrollo como expansión de libertades de Sen (2000) han dado lugar a la serie de Informes anuales de Desarrollo Humano que tienen un notable peso e influencia en las políticas de desarrollo internacionales. Pero estos informes no parecen tener una antropología explicitada, sino que más bien van surgiendo como reactivos a políticas liberalizadoras, a la corriente neoliberal generalmente asociada al Consenso de Washington, que no ha podido presentar resultados capaces de convencer a los «hacedores de política» de que el camino inequívoco del bienestar pasa por la libertad con ausencia de coacción, con llamativa ausencia de responsabilidad. La igualdad y la justicia pasan a segundos o terceros planos frente a la libertad. La economía, sobre todo la economía financiera "practicada» antes de la crisis de 2007, ha evidenciado necesitar una «ética amiga de la persona» (CV 45) que la doctrina católica dice poseer. 
La DSI y el pensamiento católico tienen una antropología muy acuñada, si bien es fruto de la complementariedad entre la razón y la fe y por tanto, no puede imponerse a no creyentes, pero sí ofrecerse. Su idea de «desarrollo humano integral» quiere recoger una idea holística del hombre (todo el hombre y todos los hombres), subrayando ante todo su trascendencia. La gratuidad del don recibido al ser creado y el amor de caridad tal como lo practicó su fundador, Jesús de Nazaret, presentan un ámbito de diálogo hasta ahora poco explorado. Concepciones románticas o neoplatónicas de ese amor, junto a la confusión de una mal interpretada caridad que se opondría a justicia, dada la práctica paternalista de algunas de sus intervenciones, dificulta este diálogo, pero no considero que sean insuperables.

Por último, el trabajo ha presentado cómo la Escuela Austriaca de economía, dentro de la tradición liberal, presenta algunas semejanzas y diferencias con la DSI que pueden enriquecer el diálogo interdisciplinar que caracteriza a los estudios del desarrollo, a la DSI $^{39}$ (CA 59) y que aquí se ha tratado de realizar.

\section{REFERENCIAS BIBLIOGRÁFICAS}

AlKIRE, S. (2010) «Human Development: Definitions, Critiques, and Related Concepts», Human Development Research Paper 01.

BAUER, P. (1972) Dissent of development: studies and debates in development economics, Harvard University Press, Boston.

Benedicto XVI (2010) Discurso a los miembros de la Academia Pontificia de las Ciencias Sociales, Ciudad del Vaticano, viernes 30 de abril.

Berger, P. y LuCKMAN, T. (1968) La construcción social de la realidad, Amorrortu, Buenos Aires.

${ }^{39}$ Dice Juan Pablo II en Centesimus Annus 59: «La doctrina social, por otra parte, tiene una importante dimensión interdisciplinar. Para encarnar cada vez mejor, en contextos sociales económicos y políticos distintos, y continuamente cambiantes, la única verdad sobre el hombre, esta doctrina entra en diálogo con las diversas disciplinas que se ocupan del hombre, incorpora sus aportaciones y les ayuda a abrirse a horizontes más amplios al servicio de cada persona, conocida y amada en la plenitud de su vocación». 
Bertina, L. (2013) «La doctrine catholique de "développement humain intégral" et son influence sur la communauté internationale du développement», in International Development Policy, Revue internationale de politique de développement [Online], 4.

Bestard Comas, J. (2003) Globalización, Tercer Mundo y Solidaridad. BAC. Madrid.

Blaug, M. (1985) Teoría Económica en Retrospección. FCE.Mexico. Buber, M. (1993) Yo y Tú, Caparrós editores, Madrid.

Bustelo, P. (1998) Teorías Contemporáneas del Desarrollo Económico, Síntesis, Madrid.

Calvez, J-Y. (1992) «La "Centessimus Annus" y el liberalismo", Selecciones de Teología, 123 (31), 245-248.

CAmacho, I. (1991) Doctrina Social de la Iglesia, Una aproximación histórica, Paulinas, Madrid.

CAMACHO, I. (2009) «Primera encíclica social de Benedicto XVI: claves de comprensión», Revista de Fomento Social 64, 629-655.

CARBONNIER, G. (2013) «Religion and Development: Reconsidering Secularism as the Norm» in International Development Policy: Religion and Development. No 4 . Geneva. Graduate Institute Publications, Basingstoke, Palgrave McMillan, pp.1-5.

Conill, J. (1996) «De Adam Smith al "Imperialismo Económico"», Claves de Razón Práctica 66, 52-56.

Consejo de Redacción de Revista de Fomento Social (2010) «Ser hermanos más allá de la globalización. El desarrollo humano integral en Caritas in Veritate», Revista de Fomento Social 65, 189-204.

CorniA, G.A.; R. Jolly \& F. SteWART (dir.)(1987) Lájustement à visage humain: protéger los grupes vulnerábles et favoriser la croissance, Paris, Economica.

Cunha, F.; J.J. HecKMAN; L. LOChNER \& D.V. MAsterov (2006) «Interpreting the Evidence on Life Cycle Skill Formation» in Erik Hanushek \& F. Welch (ed.), Handbook of the Economics of Education, Elsevier, edition 1, volume 1, number 1.

— \& Heckman, J.J. (2007) «The Technology of Skill Formation», American Economic Review, 97(2), 31-47.

EAsterly, W. (2008) «Hayek vs. the Development Experts», The Hayek Lecture. The Fourth Annual Lecture. The Manhattan Institute for Policy Research. 23-October. 
- (2014) The tyranny of experts. Economists, dictators, and the forgotten rights of the poor. Basic Books. New York.

EscoHotado, A. (2013) Los enemigos del comercio. Una historia moral de la propiedad II. Espasa. Madrid.

FERRER, U. Y RomÁN, Á.D. (s.f.) «San Agustín de Hipona», en Fernández Labastida, F. y Mercado, J.A. (eds.) Philosophica: Enciclopedia filosófica on line, URL: http://www.philosophica.info/archivo/2010/voces/agustin/Agustin.html

Gómez Caffarena, J. (1983) Metafísica fundamental, Ediciones Cristiandad, Madrid.

GonZÁlez MARSAL, C. (2013) «El pensamiento económico en las enseñanzas de Jesús de Nazaret», Procesos de Mercado X(2), 239-246.

HAYEK, F.A. (1978) Derecho, Legislación y Libertad. Vol. I «Normas y Orden»; vol. II «El espejismo de la justicia social»; vol III «El orden político de una sociedad libre». Unión Editorial. Madrid. (original 1973)

- (1990) La fatal arrogancia. Los errores del socialismo. Unión Editorial, Madrid. (original 1988).

- (1991) Los fundamentos de la libertad. Unión Editorial. Madrid. (original 1960)

- (2011) Camino de Servidumbre. Alianza editorial. Madrid. (original 1944)

Heckman, J. (2007) «The Economics, Technology and Neuroscience of Human Capability Formation», NBER Working Paper 13195;

Heckman, J. \& Mosso, S. (2014) «The Economics of Human Development and Social Mobility», NBER Working Paper 19925.

- J. Stixrud \& S. UrzuA (2006) «The Effects of Cognitive and Noncognitive Abilities on Labor Market Outcomes and Social Behavior», Journal of Labor Economics, 24(3), 411-482;

Hidalgo, R. (2011) «Liberalismo Económico y Doctrina Moral Católica», Procesos de Mercado VIII (1),121-160.

Hidalgo, A.L. (1998) El pensamiento económico sobre desarrollo. De los mercantilistas al PNUD. Universidad de Huelva. Huelva.

- (2011) «Economía política del desarrollo. La construcción retrospectiva de una especialidad académica», Revista de Economía Mundial 28, 279-320.

Huerta de Soto, J. (2004) Estudios de Economía Política, 2a ed. Unión Editorial, Madrid. 
- (2011) «Entre Mises y Rothbard. Entrevista a Jesús Huerta de Soto (1965-)», en Ravier La Escuela Austriaca desde adentro. Unión Editorial, Madrid, Cap.17, 313-344.

KoHLBERG, L. (1958) "The Development of Modes of Thinking and Choices in Years 10 to 16". Ph. D. Dissertation, University of Chicago.

K.s., J. \& ReInerT, E. S. (eds.) (2005) The Origins of Development Economics: How Schools of Economic Thought Have Addressed Development. Tulika Books and Zed Books, New Delhi and London.

- (ed.) (2005) The Pioneers of Development Economics. Great Economists on Development. Tulika Books and Zed Books, New Delhi and London.

LENSKI, G. (1966) Power and Privilege: A Theory of Social Stratification, McGraw-Hill, New York.

Lonergan, B. (1994) Método en Teología. Sígueme. Salamanca.

López-Casquete de Prado, M. y Margenat Peralta, J.M. (2013) «El concepto de desarrollo humano integral en la doctrina social de la iglesia: De Juan XXIII a Benedicto XVI», Proyección: Teología y mundo actual, 250, 283-304.

MARChESI, J. y Sotelo, J. (2002) «Ética, crecimiento económico y desarrollo humano», Trotta, Madrid.

Margenat Peralta, J.M. (2012) «Un nuevo modelo de desarrollo y de economía», Revista de Fomento Social 268, 687-691.

Meier, G.M. \& Seers, D. (eds.)(1984) Pioneers in Development, Oxford Univ. Press for the World Bank. New York.

MeLé, D. et al. (2010) El desarrollo humano integral: comentarios interdisciplinares a la encíclica Caritas in Veritate de Benedicto XVI, Iter, Barcelona.

Mises, L. Von (2009) El Socialismo. Análisis económico y sociológico. $6^{\mathrm{a}}$ ed. Unión Editorial. Madrid. (original 1922)

- (2011) La Acción Humana: Tratado de Economía. 10ª ed. Unión Editorial. Madrid. (original 1949).

MoRIN, J. (2007) «Gestión como auto-apropiación emprendedora», material didáctico disponible en http://lonerganmorin.files. wordpress.com/2007/05/lonergan_metodo1.doc

NovaK, M. (1993) Catholic Ethic and the Spirit of Capitalism, Free Press. 
PAnCoRbo, A. (2011) «Caritas in Veritate: puntos para el diálogo entre la teoría económica y el Magisterio Social», Procesos de Mercado VIII (1), 51-90.

Piaget, J. (1932) The Moral Judgment of the Child. London: Kegan Paul, Trench, Trubner and Co.

PNUD (1999) Informe sobre el Desarrollo Humano. Mundi-Prensa. Madrid.

Pontificio Consejo Justicia y Paz (2005) Compendio de la Doctrina Social de la Iglesia. BAC y Planeta. Madrid.

- (2008) «Nota de la Santa Sede sobre la Financiación del Desarrollo en vísperas de la Conferencia de Doha», 18 de noviembre.

- (2011) «Por una reforma del sistema financiero y monetario internacional en la perspectiva de una autoridad pública con competencia universal», Ciudad del Vaticano, 25 de octubre.

RAVIER A.O. (2011) La Escuela Austriaca desde adentro. Historias e Ideas de sus pensadores. Volumen I. Unión Editorial, Madrid.

Ricoeur, P. (2004) Finitud y Culpabilidad. Trotta. Madrid.

Rodríguez Braun, C. (2010) «Del buen samaritano a Robin Hood», en Diez ensayos liberales, Lid, Madrid, cap.3.

- (2011) «Tensión económica en la Centesimus Annus» en Economía de los no economistas, Biblioteca Carlos Rodríguez Braun. Acción Empresarial, Madrid, pp.93-110.

RoEMER, J. E. (1993), A pragmatic theory of responsibility for the egalitarian planner, Philosophy and Public Affairs 22: 146-166.

- (2013) «Economic Development as Opportunity Equalization», forthcoming World Bank Economic Review doi:10.1093/wber/ lht023, World Bank Policy Research Working Paper 6530.

Romero, J.J. (2009) «Desarrollo y cooperación», Revista de Fomento Social 64, n709-725.

Rothbard, M. (2013) Historia del Pensamiento Económico, Unión Editorial, Madrid.

Rubio de Urquía, R. (2014) «Acción Humana y Doctrina Social de la Iglesia: Un Esbozo de «Economía» en la Encíclica "Caritas in Veritate"», en Rubio de URquía, R. y Pérez-SobA, J. (eds.) La Doctrina Social de la Iglesia. Estudios a la luz de la encíclica Caritas in Veritate, AEDOS y BAC, Madrid, pp.59-248.

—;E.M. Ureña y F. MuÑoz Pérez (eds.) (2005) Estudios de Teoría Económica y Antropología. Unión Editorial. Madrid. 
SAVATER, F. (1988) Ética como amor propio, Mondatori, Madrid.

Schumpeter, J.A. (2012) Historia del Análisis Económico. Ariel. Barcelona.

Schwartz, P. y Martín, V. (1991) «La ética del amor propio en Spinoza, Mandeville y en A. Smith», Información Comercial Española 691, 31-43.

- (1994) «La moral del amor propio y los fundamentos éticos del capitalismo en el pensamiento de Adam Smith», en R. Rubio de Urquía, y E. Menéndez Ureña, Economía y dinámica social. Universidad Pontifica Comillas. Madrid.

- (2007) «Introducción a la antropología del capitalismo», Papeles «Lucas Beltrán» de Pensamiento Económico. Documento de Trabajo $N^{\circ} 1$.

- (2007b) En busca de Montesquieu. La democracia en peligro. Ediciones Encuentro. Madrid.

SELINGER, L. (2004) «The Forgotten Factor: The Uneasy Relationship between Religion and Development», Social Compass 51(4), 523543.

Sen, A.K. (2000) Desarrollo y Libertad. Planeta. Barcelona.

Sicre, J.L. (2013) «Jesús y la riqueza», Proyección: Teología y mundo actual 250, 265-282.

ZAMAGNI, S. (2010) «Globalization: Guidance from Franciscan Economic Thought and Caritas in Veritate», Faith E Economics 56, 81109.

ZanotTi, G.J. (2011a) Antropología filosófica cristiana y economía de mercado, Biblioteca Austriaca, Unión Editorial, Madrid.

- (2011b) «La filosofía, la economía y su método», en A.O. RAVIER La Escuela Austriaca desde adentro. Unión Editorial, Madrid, Cap. 19, 363-384. 


\section{ANEXO \\ EVOLUCIÓN DEL PENSAMIENTO PONTIFICIO SOBRE EL LIBERALISMO.}

1. Pío IX condena el liberalismo (Syllabus 1864, punto 80 y encíclica y Quanta Cura) junto al progreso y la moderna civilización.

2. León XIII en RN 1891: no aparece la palabra liberalismo, pero concede un papel insustituible al Estado que «debe velar por el bien común como propia misión suya» (RN 23) pero sin absorber al individuo ni a la familia (RN 26).

3. Pio XI en QA 1931: aparecen 6 referencias al liberalismo y son más bien negativas («adictos al liberalismo», QA 30), pero entendido como corpus que se opone la RN y a la «cuestión social» (obrera QA14) pero en igual plano que al socialismo: «tengan presente todos que el padre de este socialismo educador es el liberalismo, y su heredero, el bolchevismo» (QA 122).

4. Juan XXIII en MM 1961 continúa la doble condena a los sistemas: «trabajadores y empresarios deben regular sus relaciones mutuas inspirándose en los principios de solidaridad humana y cristiana fraternidad, ya qué tanto la libre competencia ilimitada que el liberalismo propugna como la lucha de clases que el marxismo predica son totalmente contrarias a la naturaleza humana y a la concepción cristiana de la vida». (MM 23). En PT centra las relaciones entre individuos, pueblos y mundiales en los valores del amor, justicia, verdad y libertad.

5. Pablo VI en PP hace cuatro referencias al liberalismo. En PP 26 se le critica entendiéndolo como: «el provecho se consideraba como el motor esencial del progreso económico, la concurrencia como ley suprema en la economía, la propiedad privada de los medios de producción como un derecho absoluto, sin límites y obligaciones sociales que le correspondieran». En PP 34 se critica la tecnocracia y avisa que puede traer peores males que los que trajo el liberalismo, ante todo por considerar el provecho «como el motor esencial del progreso económico, la concurrencia como ley suprema en la economía, la propiedad privada de los medios de producción como un derecho absoluto, sin límites y obligaciones sociales que le correspondieran». El número 58 es claro en mostrar las posibilidades y limitaciones del liberalismo: 
58. Claro, pues, aparece que la llamada ley del libre cambio no puede, ella sola, seguir rigiendo las relaciones públicas internacionales. Puede, sin embargo, aprovechar bien cuando se trata de partes no muy desiguales en potencia económica: es un estímulo del progreso y una recompensa a los esfuerzos. Por eso, las naciones muy industrializadas juzgan que en dicha ley existe clara la justicia. Pero de otro modo se ha de pensar cuando se trata de condiciones muy desiguales entre los países: los precios formados "libremente" por los negociadores pueden conducir a resultados totalmente injustos. $\mathrm{Ha}$ de reconocerse, por lo tanto, que el principio fundamental del liberalismo, como norma de los intercambios comerciales, se halla aquí en no recta posición.

Pablo VI en OA 1971 lo que critica es la ideología liberal:

35. Por otra parte, se asiste a una renovación de la ideología liberal. Esta corriente se apoya en el argumento de la eficiencia económica, en la voluntad de defender al individuo contra el dominio cada vez más invasor de las organizaciones, y también frente a las tendencias totalitarias de los poderes políticos. Ciertamente hay que mantener y desarrollar la iniciativa personal. Pero los grupos cristianos que se comprometen en esta línea, ¿no tienden a su vez a idealizar el liberalismo, que se convierte así en una proclamación a favor de la libertad? Estos grupos querrían un modelo nuevo, más adaptado a las condiciones actuales, olvidando fácilmente que en su raíz misma el liberalismo filosófico es una afirmación errónea de la autonomía del ser individual en su actividad, sus motivaciones, el ejercicio de su libertad. Por todo ello, la ideología liberal requiere también, por parte de cada cristiano o cristiana, un atento discernimiento.

6. Juan Pablo II continúa la doble crítica a las ideologías. En LE 1981 dice:

Este conflicto, interpretado por algunos como un conflicto socioeconómico con carácter de clase, ha encontrado su expresión en el conflicto ideológico entre el liberalismo, entendido como ideología del capitalismo, y el marxismo, entendido como ideología del socialismo científico y del comunismo, que pretende intervenir como portavoz de la clase obrera, de todo el proletariado mundial (LE 11). 
Y en LE 13 le critica en cuanto puede mantener una supremacía del capital sobre el trabajo humano:

No se ve otra posibilidad de una superación radical de este error, si no intervienen cambios adecuados tanto en el campo de la teoría, como en el de la práctica, cambios que van en la línea de la decisiva convicción de la primacía de la persona sobre las cosas, del trabajo del hombre sobre el capital como conjunto de los medios de producción.

Y en LE 14 por su concepción de la propiedad privada, que también es criticada al colectivismo, por no subordinarse al principio de destino universal de los bienes:

El citado principio, tal y como se recordó entonces y como todavía es enseñado por la Iglesia, se aparta radicalmente del programa del colectivismo, proclamado por el marxismo y realizado en diversos Países del mundo en los decenios siguientes a la época de la Encíclica de León XIII. Tal principio se diferencia al mismo tiempo, del programa del capitalismo, practicado por el liberalismo y por los sistemas políticos, que se refieren a él. En este segundo caso, la diferencia consiste en el modo de entender el derecho mismo de propiedad. La tradición cristiana no ha sostenido nunca este derecho como absoluto e intocable. Al contrario, siempre lo ha entendido en el contexto más amplio del derecho común de todos a usar los bienes de la entera creación: el derecho a la propiedad privada como subordinado al derecho al uso común, al destino universal de los bienes.

En SRS no aparece ninguna referencia al liberalismo, pero en CA 1991 aparecen dos.

En CA 60 se hace referencia a que ya León XIII mantenía que para solucionar la «cuestión obrera» se debía contar con la participación de todos, y a eso se oponen las ideologías del liberalismo y marxismo, pero que desde entonces ha habido cierto cambio:

El mundo actual es cada vez más consciente de que la solución de los graves problemas nacionales e internacionales no es sólo cuestión de producción económica o de organización jurídica o social, sino que requiere precisos valores ético-religiosos, así como un cambio de mentalidad, de comportamiento y de estructuras. (CA 60). 
7. Benedicto XVI no menciona al liberalismo en CV 2007 (aunque «libertad» aparece 37 veces), así como tampoco Francisco en EG 2013 (con 16 referencias a «libertad» la mayoría de ellas en el sentido de libertad religiosa) con crítica expresa a la «libertad de mercado» en la versión de la «teoría del derrame» (EG 54) al suponer que «todo crecimiento económico, favorecido por la libertad de mercado, logra provocar por sí mismo mayor equidad e inclusión social en el mundo». En la última encíclica LS 2015 tampoco hay referencias al liberalismo, y 20 a «libertad» la mayoría de ellas en un sentido crítico por no conciliar otros valores como la sostenibilidad. Merece la pena destarase el número 129 que une libertad, empresa y bien común:

Para que haya una libertad económica de la que todos efectivamente se beneficien, a veces puede ser necesario poner límites a quienes tienen mayores recursos y poder financiero. Una libertad económica sólo declamada, pero donde las condiciones reales impiden que muchos puedan acceder realmente a ella, y donde se deteriora el acceso al trabajo, se convierte en un discurso contradictorio que deshonra a la política. La actividad empresarial, que es una noble vocación orientada a producir riqueza y a mejorar el mundo para todos, puede ser una manera muy fecunda de promover la región donde instala sus emprendimientos, sobre todo si entiende que la creación de puestos de trabajo es parte ineludible de su servicio al bien común (LS 129). 
